\title{
Mindfulness of Emotions and Thoughts, and the Non-location of Mind
}

\author{
Ajahn Amaro ${ }^{1}$ \\ Accepted: 24 August 2021 / Published online: 16 October 2021 \\ (c) Amaravati Publications 2021
}

As we find ourselves more able to establish the quality of inner spaciousness, attending to the present, and as we learn to listen to the inner nada sound as a way of sustaining more of an open inclusivity in our mental world, this can help us to develop a quality of greater mindfulness in the emotional realm. If you have watched your mind closely, you will probably have noticed how certain sense impressions, memories, ideas and mental images carry an emotional charge. The mind gets swept away, drawn in and carried off far more easily when there is an emotion present. So it's very helpful for us to apply meditation practice to cultivating mindfulness of emotion; in this way, we develop an understanding of how emotion works and how we can work with it.

It's important to recognize that we are not trying to stifle emotions or to steer our lives towards a state where we do not feel anything at all. Buddhist practice is not aimed towards neutralizing, nullifying our emotional nature. It is more to do with understanding emotion, seeing how it works and learning how to guide it skillfully.

Whenever we experience any kind of emotion, whether it's positive, negative or neutral; whether it is an inspiration or excitement, joy or grief, sadness, anger or fear; whether it's wholesome or unwholesome, bright or dark; some kind of physical sensation always accompanies the emotion. There is a physical corollary, a sensation which goes with every kind of emotional state. And in this physical corollary there is no fixed pattern that applies to all of us-everyone has their own particular imprint. The ways in which each of us will experience emotion as a physical feeling are unique, but everyone will feel some sort of physical sensation accompanying emotional states. And that physicality can be a very helpful entry point, a useful tool for steering the mind towards emotional balance. It helps us to develop

Ajahn Amaro

ajahn.amaro@gmail.com

1 Amaravati Buddhist Monastery, Great Gaddesden, Hemel Hempstead HP1 3BZ, Hertfordshire, UK mindfulness and wisdom and to integrate them with our emotional experience.

If you have a particular emotional habit that you want to understand-for example, if your mind is very taken up with grief and sadness at the loss of a loved one, or you are particularly prone to irritation and your mind is always grumbling about life, or you are prone to anxiety and fearyou can use meditation on physical sensation to deliberately explore those particular habits and understand them more completely. To give an example, after I had been a monk for about six or seven years, I realized that my basic relationship to life was one of anxiety. This anxiety was so strong, pervasive and unrelenting that I hadn't even realized I was anxious. The anxiety was just like the force of gravity, it was there all the time. What I mean by this is that it suddenly dawned on me one day that my basic relationship to life was, "If it exists, worry about it". That was my fundamental response to life: "Whatever it is, whether it's a brick or a tree or a cloud or a human being, if you perceive it, worry about it". This discovery was surprising to me, because as a "full-time" meditator I had been watching my experiences and traits for a number of years. I had been looking closely at the mind and learning how it works, and so I was astonished to discover that I had overlooked such a strong habit. Worry was such a continuous presence that I didn't even realize I was worrying. It seemed utterly normal. The feeling I had was, "Of course, if something exists, then you should worry. It's irresponsible not to be worried. You're not doing your duty if you're not fretting".

I realized I needed to learn about this, to understand this anxious habit and how easily the mind became caught up in it. I was very fortunate to be studying under Ajahn Sumedho's guidance at that time and it was through listening to his advice and following his guidance that I learned how to use the physical sensations of an emotion. He would explain that when you're caught up in an emotion, the tendency is for your attention to go to the thing you're worried about; what somebody thinks about you, or whether you're going to be able to get to the airport in time to catch your plane. The attention tends to focus on the object of worry. But when that 
happens, you miss the actual experience of fear. You miss what is happening on the subject side because the attention is going to the object.

To assist in this investigation of emotion and help break the habit of fixating on the object, Ajahn Sumedho used to encourage us to bring up our emotions deliberately in meditation.

First draw your mind to a quality of calm and stillness: focus the attention on the present by using the breath or listening to the nada sound and allow as much inner spaciousness as possible. Let the mind relax, be open, attentive and aware and then deliberately bring up something that causes an emotional reaction. For example, if you are working with anxiety, call to mind something that you know would trigger it, a simple feeling like "I got it wrong and people will be upset with me". When you deliberately launch that emotion, you don't need a whole big story; you just need something to light the fire, as it were. Just take a simple phrase like "I'm late!" or "They don't like me". Then deliberately take your attention away from all the verbal creations into which the mind starts to launch, draw your attention away from all the conceptualizing and consciously bring it into the body. Where does that feeling of fear sit? Where is that feeling of indignation, desire or resentment? Where is it? How does it feel? What is its temperature? What is its quality, its texture? Where do I feel it?

With fear, I found that there was almost invariably a knot of tension down in the gut, in the solar plexus area. There'd be a tightening of the stomach, the abdomen.

Having triggered that emotion, bring your attention to the sensation itself. It takes effort to maintain focus and not let the mind go into storytelling. This is why it is important to establish a quality of steadiness and clear attention at the beginning. Then you simply use that physical sensation as the meditation object; you notice it and then cultivate a quality of acceptance, a radical acceptance of that physical sensation.

What was really striking to me in this instance was to realize that this habit of fear and anxiety was driving my whole life. I was either doing everything I could to get away from that fear and reach a place where I wasn't feeling it, or I was hunting for something to lessen the fear, to make it disappear. It was as if this fear was the most terrible, awful feeling and I had to get away from it. But when you attend calmly to fear, you see that it is Mother Nature's protection. Fear is not a disease. It is how living creatures protect themselves. Creatures who aren't afraid are eaten, fall off cliffs or are hit by oncoming traffic. So fear is useful.

Years ago, I was on retreat in the forest at Chithurst. I was sitting on a five-barred gate watching the sun coming up early in the morning and there were deer grazing out in the field, nibbling the young corn. Then I sneezed and the deer poked their heads up, saw me on the gate and ran off across the field. I thought: "Oh, poor things, their lives so dominated by fear and terror. This innocent monk sneezes and they race away". And then this thought followed: "That's how they stay alive. That's why deer have big ears and big eyes, so they can tell when there is any danger around. Their fear helps them to stay alive".

But fear becomes problematic when it overspills its boundaries. For us, fear is not just employed now to keep us from being eaten by saber-toothed tigers or mountain lions, or shot by enemy tribes-it has become a pervasive, continual and stressful habit.

This is what I became aware of when I brought attention to that physical sensation of fear. After spending so much time, effort and energy trying to get away from fear, when I brought attention to what it is really like, to the feeling of fear as a sensation, as a presence, without any kind of commentary about it, there was the somewhat disappointing realization that fear isn't really all that bad. I asked myself, "Why do I spend so much time, effort and energy trying to get away from this? Is it even as bad as a headache or a stone in the shoe? It's not as bad as a toothache, let alone a broken bone or anything like that. It's really not that terrible, not that unbearable at all. It is not pleasant. I am not pretending that it is delightful or sweet, but it is really not that bad".

It is because of the conditioning and reactive process that we have the sensation of panic and dread which causes us to want to escape fear, to reach a place where we will never feel it. We step back from the edge of the cliff, we get away from where the danger is, we turn the light on: "Okay, we can see-fine, there are no ghosts". There is a feeling of relief.

In this practice, once you have treated the emotion consciously, just stay with that physical sensation for a few minutes. Be as fully attentive as you can be and develop an attitude of acceptance. Be open to it. Let the emotion be fully known and felt as a physical sensation, with as little commentary or judgement as possible. Then after five or ten minutes or so, consciously start to let it go. Let the body relax. Relinquish the tension and let the feeling dissolve and fade away. Ajahn Sumedho used to emphasize not being in a hurry to get away from the emotion or wiping it out, but just letting it fade on its own. Sometimes with a particularly strong emotion, long-standing resentment, painful grief or intense regret, for example it can take just five seconds to trigger the emotion and then forty-five minutes to let go of it. But if it takes that long, then it takes that long. Just let it fade in its own time. Let it end according to its own pace. You allow it to cease rather than try to force it to end or suppress it.

When the emotion has finally run its course and faded away, the last piece of this practice is to return to that quality of spaciousness and clarity again, to the nada sound. Let there be attention to the open inner space of the mind. In this process, you have watched an emotion come into being. It 
has been born. It has done its thing. It has risen to its peak, it has gone through its whole cycle, and then it has faded away and gone back to nothing again. You have watched the whole life-cycle: birth, flourishing, fading and dissolving. You watched it throughout the entire process. You have seen it come out of nothing and go back to nothing. You have seen the emotion clearly from its birth to its dissolution, and during the course of its presence, there has been a quality of acceptance; you have accepted the emotion completely and wholeheartedly, or at the very least you have accepted the physical sensation which comes from the emotion.

And the interesting and mysterious thing is that because we have accepted and had an open and unbiased attitude towards the physical sensation, to some degree we have also accepted where the emotion has come from. The heart comes into accord with that habit of fearing or the source of that conflict, that grief, and to some degree there is an acceptance and a coming into harmony with its origin, its source. It is like drinking water from a stream-when you drink water from a stream, you have also drunk from the source of the stream. You taste where the water has come from. This has a very powerful effect in helping us to work with emotions. Once you have developed this ability in the quiet and stillness of a retreat or a formal period of meditation practice, you begin to be able to do it more generally.

Once I had learned to use this meditation to identify my fear and anxiety, whenever anxiety arose about anything during the course of the day, I would make it my practice to focus my attention on the solar plexus. I would take a moment to become conscious of the physical sensation of that emotion, and then I would let myself relax. When you start developing this sort of ongoing awareness and bringing it into real-life situations that cause it, you're not just conjuring it up out of your own imagination anymore. You are dealing with real emotions in real-life situations. What happens then is a curious alchemy. Let's use the example of anxiety again: you bring your attention to that feeling in the body, you let the body relax, and then you ask yourself what you were worried about. Almost invariably the mind will take a couple of moments to find the answer; for those few moments, it will be at a loss, and during that short time, you have unplugged the anxiety programme. There was no "thing" to be worried about. It truly dawns on you that if you don't make it a problem, it isn't a problem. If I don't create it as a problem, if I don't create a thing to be worried about, there isn't actually anything to be worried about.

The mind makes things into problems. When we are annoyed and thinking, "It shouldn't be this way! That's outrageous! How can she do that? It's totally wrong!" these are all just creations of our mind, they are our mental constructions. If we don't construct them, they aren't there.

The same goes for an emotion like desire. Once you've let go of that desire, you ask yourself, "What was I wanting so badly?" And then, even if it's for just half a second, watch how the mind has to reconstruct that desire. At first you were thinking, "I've got to have it!" but then for half a second you were fine without it. In fact, you couldn't even remember what you were wanting.

Some might think this is a pointless mind-game, but I can vouch from my own experience that it is a very radical way of unplugging those emotional habits. It takes away the causes for emotional reactivity. It is a practice that eases the bondage of the heart to loves and hates, inspirations and depressions, fears and anxieties, reactions, griefs, regrets and excitements. So the identification and the confusion with emotions are radically changed, are altered in a fundamental way.

My habit of fear and worry was extremely strong, so for two or three years this was my main practice. This engagement with the emotion was the main effort I made. Every day at the beginning of the morning sitting, I would set the intention: "Today, whenever anxiety or fear of any kind arises about anything whatsoever, I will bring my attention to it and be conscious of it, let it be fully known and let go of it". I would prime myself for that every day. After working with worry like that for two or three years, it had changed quite radically. It had been dissolved, it stopped being an issue. That was quite a remarkable change in my experience of the world. I knew what life was like and I didn't have to worry about it all the time. It felt quite revolutionary at first. Sometimes I would think, “This can't be right-I'm not doing my job here. The world can't carry on unless I'm worrying about something". But then I would realize it was absolutely fine.

Each one of us has our own favorite emotional flavors. Some of you might think you haven't got any problems with emotions. And if that's true-sadhu! I feel much muditā for you. But if you do feel that you have problems with an emotion, what you are able to do in this practice is understand that problems don't come from having emotions. The emotional world only becomes problematic when there is entanglement, when the heart is caught up and identified with loving, with hating, with fearing, desiring, grieving, regretting or hoping. It is identification and entanglement with emotion that cause the problems. When the identification and entanglement are not there, we simply feel the flow of emotion-happiness, unhappiness, liking, disliking. Emotion can flow through us. We can know it and it can pass through without confusion. Then we can empower, strengthen and act on emotions that are wholesome and beautiful, like kindness, compassion and well-wishing. We are able to recognize emotions like resentment, anger, jealousy, fear as being harmful and destructive. They flow through, but we don't act on them. As Luang Por Chah said about his angry tendencies, "Yes, I have lots of anger but I don't use it".

Another aspect of developing this quality of internal spaciousness is that it also gives us a bit more of a perspective 
on conceptual thought. Mindfulness of thinking is a practice which Ajahn Sumedho would teach in a similar vein, deliberate thought to learn how to watch thought. You deliberately think something - again, this might seem like a pointless mind-game, but it can be very handy. The Ajahn would suggest taking a simple, completely bland thought like, "Today is Wednesday" - very emotionally uncharged, an ordinary non-contentious statement. First, bring the mind to a quality of quietness, spaciousness, stillness; then deliberately think that thought. You watch the thought begin. You notice the space before it, and then you think "Today is Wednesday" or something equally neutral. You notice the space before the thought, then you plant it and notice the space after it. Do this as a little exercise, as if you're learning a musical instrument. There you have your exercises, practicing your scales over and over again- $\delta \delta \delta \ldots . . . \delta \delta \ldots . \delta \delta \delta$ - so that you learn. You teach your fingers how to make those particular notes. Similarly, you can use a simple exercise like this to train yourself how to watch conceptual thought. By taking something that is totally bland to begin with, like "Today is Wednesday", once you get the hang of doing the exercise with that thought and you can see its beginning, middle and end, you can start with something a bit more complicated, a bit more involved.

You can also teach yourself to notice the space between the words: "Today [space] is [space] Wednesday". Even as a thought is passing through, there is space between the words, and in that space there is no thought. This practice of seeing emptiness between and within thoughts is very helpful, because as we have seen with emotion, our attention is caught by objects. The mind goes into the content of a thought, a concept, a memory or a set of ideas, and we become swept up in it if we don't simply see it as a thought: "Oh-this is a thought". Likewise with emotions or feelings; we are swept up in them if we don't see them for what they are: "Oh-this is an emotion, this is a feeling". If we don't see these mental activities for what they are, we become swept up in the content and carried away. Conceptual thinking can be very compelling. We start figuring things out, planning things or remembering things, and whoosh! The mind so easily gets swept up in the content.

The ability to watch a thought as just a thought is tremendously helpful. In developing vipassana $\bar{a}$, the capacity to watch the mind is built around letting go of the content and learning to watch the process. We therefore practice this simple exercise over and over again, learning how to think deliberately - we watch a thought or make a thought come into being, we focus on it as it is present, and we let it finish. We learn how to do this with a bland and neutral thought of our own choosing. Then, when the mind conjures up its own thoughts, memories or opinions, rather than just buying into them, getting caught up with them and launching into a fantasy, a plan, a memory or a belief, there can be clear wisdom: "Oh - this is an opinion. This is a memory. This is a story my mind likes to tell. That's all". You don't have to push it away, you don't have to grasp hold of it. You can know it as merely a pattern taking shape in the mind.

Ajahn Sumedho would also recommend using our sensory experience of space. When listening to a talk or reading the words on a page, our attention goes to the words rather than the silences or the spaces between the words. After all, words are more interesting than silence. It's like the space in a room - the people and objects in the room are more interesting than the space between them. People and objects have names and histories. People have gender, they have ages, they have different-colored clothing, so our attention is caught by those particularities, but the space between people is pretty much all the same. Spaces don't catch our attention. But if we don't notice space, we are missing something. We are always absorbing attention into one condition after another. We are not able to keep a perspective on life because our mind goes into judgement or comparing, into criticism, liking and disliking. So Ajahn Sumedho suggests the simple practice of noticing space. Again, this is not very complicated or demanding. Just take a moment when you come into a room to notice the space around people, the space between people. When you hear a talk or read a book, notice the silence between the words. This doesn't take a lot of attention.

When we bring awareness to what the space in a room is like, we realize that it actually contains more space than people or objects, and that while the space may not be very interesting, it is very peaceful. Space is very calming and delightful in its own way. We can improve our relationship to emotion and conceptual thought by this simple practice; we can learn to keep emotion and thought in perspective by noticing the space around them. We can support this perspective by developing the practice of noticing space in the world around us.

Space is always there, in the places where we go and the things that we do. Even on a noisy, crowded train or bus, even on the London Underground, take a moment to notice the space. Don't get caught up in the noise, the smell and the movement. Take a moment to say to yourself: "Look-there is space here too".

When we notice space there is a levelling effect. Rather than the mind getting caught in the judgement of liking and disliking, and becoming involved in patterns of reaction, when we notice the space that is around and within things there is equanimity, serenity. We are not so drawn in by the details of what is occupying or coloring that space-those details are held within a larger picture.

When we start to develop these kinds of contemplation, contemplations on space, emotion, and experience, we begin to recognize that just as thought and emotion are known within the mind, what we see, hear, smell, taste and touch is 
also known within the mind. So right now, in this very room, everything you are experiencing is known within the mind. Though you are in a room, you might equally say the room is in your mind. Everything you've ever known throughout your entire life has been known through the agency of your mind. In no way have any of us ever known anything through any other medium. Everything we've ever experienced since we were tiny babies has been known through the avenue of our minds. So we have only ever experienced our mind's representation of the world. In conventions of speech we say, "My mind is in here and the world is out there", but actually the world we experience is sight, sound, smell, taste, touch being woven together into a (usually) coherent form within the mind. In short, the world is in our mind.

Now, the Buddha-Dhamma is not a philosophy of what is called solipsism, the philosophical belief that there is no world outside our minds, that the world is all just our dream or a kind of invention. Some philosophers have taken this to be true; that if you stop looking the world disappears, that the world is completely invented by our mind. This is not the teaching of the Buddha. The Irish philosopher Bishop Berkeley talked about the oak tree in the quadrangle of his college garden. He used to ask his students whether the oak tree continued to exist if you weren't looking at it. It was one of his proofs of the existence of God; the fact that the oak tree kept existing while you weren't looking at it meant that somebody must be looking at it, and if somebody was looking at it, that somebody was probably God. This inspired a bored philosophy student to write this limerick:

There was a young man who said, "God

Must think it exceedingly odd

To find that this tree

Continues to be

When there's no one about in the quad."

Which inspired this limerick in response:

"Dear Sir, Your astonishment's odd,

I am always about in the quad.

And that's why this tree

Will continue to be.

Signed, Yours Faithfully, God"

Buddhists don't think like that.

We don't say that the world is entirely fabricated by the mind and that other beings don't really exist, that everything is just a dream the mind conjures into existence. For Buddhists, our version of the world is constructed and patterned by our own conditioning; the world that we experience is built up, formed and framed by the experiences of a lifetime. The fact that I speak English, that my mind thinks in this particular language or that I have these particular life experiences is all part of my conditioning as a human being. If I was a spider, this room would be very different; the humans in it would be really boring, but the things a spider can eat would be really interesting. If we are willing to consider the possibility that the world we experience is in fact fabricated, formed by the patterns of consciousness within our minds, we will see that this is indeed true. Being able to experience the world in this way changes our relationship to it. If the world is in our mind, there isn't really an "out there". It's all "in here". It's all known here. It's all patterns of mental events taking place and forming within awareness. When we are able to shift perception in this way, we are able to move the flow of our thoughts and events from "out in the world", and recognize that it all happens in here.

There is a quality of integration, a sense of wholeness, which comes with opening the mind in this way. This integration can be particularly apparent in walking meditation. There can be the feeling that "I" am walking and the world around me includes trees, birds, grass and the sky, and at night the stars and planets. But then we recollect that the world is in the mind, that it all happens here. There is no "there". It's all "here". It is all known within the same sphere of consciousness, of awareness.

When you shift the perception in this way, notice how it affects you. Again, you might feel this is just another mindgame, but the point of these exercises is that they change us. We are able to recognize the fact that when we close our eyes, the visual world vanishes. When we open our eyes, the visual world reappears and everyone again comes into being. We directly know the fact that our experience of the world is fabricated by our senses-the world that we know is all happening here, within this mind. It is known here. Through being able to see that, what we experience is a continuous flowing process, a single integrated process. This makes it easier to abide in the quality of knowing, awakened awareness. The heart receives and knows that flow of perception and experience. And along with attending to the different patterns of perception, thought, feeling, of movement, flow and change, there is also a wonderful quality of stillness. Just as the space of this room contains all the movement of all the people who come and go and change within it, and is a framework for the movement, similarly, there is a quality of awareness in our minds which is the framework, which contains and accommodates all the movement.

Towards the end of Luang Por Chah's teaching career, just before he had a stroke and lost the ability to speak, he used to ask people, "Have you ever seen still water?"

"Yes. Just like in that glass. This water is still. It's not moving."

"Have you ever seen flowing water?"

"Well, yes, I've seen flowing water."

"Have you seen still, flowing water? Water that's both flowing and still?" 
And people would think they had misheard him. "Still, flowing water? What is he talking about?"

Luang Por Chah would say that the mind is like still, flowing water. It flows insofar as its perceptions, thoughts and moods, its sights, sounds, smells, tastes, touches, thinking and emotions, all come and go and change. There is a continuous flow. But there is also stillness. There is that which is aware of all the mental activity of perception, of thought, of feeling - and that awareness is not going anywhere. That awareness is outside of the world of space and time. That awareness is perfectly still. It is not something which is subject to movement or change. It is the ever-present quality of knowing- "the one who knows", that which is aware.

So your mind is like still, flowing water. There is stillness and there is movement; the two interpenetrate and permeate each other completely and without conflict. This is a helpful image to bear in mind.

We learn to see that there is movement, like the body moving up and down on the walking meditation path, but that which knows the movement isn't going anywhere. That which knows the movement is outside the realm of time and space. It is ever-present, yet it is not caught up in the movement. While you are walking, at the same time as there is the perception of the body moving, the body is walking up and down, but that which knows the body is always here. Just as in your entire life, everything you have ever known or experienced has happened through your mind-it has only ever happened here.

Throughout your life, you will always be "here". When you were in the shrine room at Amaravati, or even when you were a little baby in your hometown and didn't think in words, you have always been "here"; there was always a "here-ness", wherever you were. So we bring our attention to this quality to which Ajahn Chah was referring, this quality of stillness in the still flowing water of life, this quality that is always happening "here". This knowing quality is free from bondage to the realm of time and space. It is unlocated.

Buddhist teachings refer a lot to anicca, dukkha, anattā, impermanence, unsatisfactoriness and not-self, and how to use them as reflections to loosen the habits of attachment and identification. Those habits can be quite subtle, pervasive and strong.

The feeling of self is a particularly strong habit. So in our practice, we emphasize the importance of clearly seeing the self-creating habits of the mind and learning how to loosen the grip on those habits; how to let them go completely and free the heart from self-view. But those bonds can be invisible as well as strong. Even when the self-creating habit is seen clearly, and even when there is a letting go of it, there can still unbeknownst to us, be a strong bondage.

Years ago when I was on a winter retreat at Abhayagiri Monastery in California, about three or four weeks into the retreat my mind was very quiet and the practice was very steady and strong. It was a very quiet and supportive retreat environment, so it was becoming easy to see the quality of

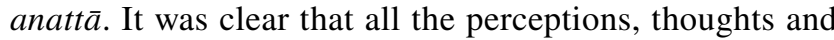
memories, the body and feelings, were not-self, not me, not who and what I was. There was a kind of obviousness and naturalness to that insight.

After a while, though, there was a strange feeling of being cramped, a quality of containment or limitation. I thought, "What is this about?" There was clear seeing that things are anicca, dukkha, anattā, not-self, empty of substance; but there was also this strange limitation, a strange kind of tension in the system. And it suddenly dawned on me and became clear, "Ah! It's all happening here". I realized that it was the mind creating the feeling of locatedness, that everything was happening in "my" mind, even though the usual crystallizations of the "I" feeling were absent. I realized my mind was attached to the notion that it was happening "here", at this spot.

At the risk of being too abstruse, I feel this is a helpful thing to look at. It was clear to me that until that point I hadn't actually seen the attachment to the feeling of place or the feeling of location that the mind creates-the sense of "here-ness", in this spot, this geographical centre where things are felt.

I don't know if any of you have intuited or felt this but it was very striking to me at that time. I suddenly realized there was an attachment to the idea that awareness was happening in this place, this location. So I began to look at that very feeling of locatedness and the sense of things happening here. I used a very simple and straightforward reflection: bringing to mind the word "here" or saying to myself, "It's all happening here". By bringing the attention to it, the word "here" began to seem absurd. Then a whole extra layer of letting go was able to happen.

Awakened awareness, knowing, is free from bondage to the realm of time and space as well. It is timeless and unlocated.

Shortly after that, I came across a sentence in a Dhamma talk by Ajahn Mahā-Boowa. He talked how this very insight had played a radical role in his own spiritual development. It was just after the time when his teacher Venerable Ajahn Mun had passed away. Ajahn Maha-Boowa was doing walking meditation, and out of nowhere this thought appeared in his mind: "If there is a point or a centre to the knower anywhere, then that is the essence of birth in some level of being".

If "the knower" considers itself to have a location or a centre, then that is the essence of birth in some level of being. This means that this is where the mind gets caught. Avijja happens right there. Until that false locatedness is recognized as a quality of grasping, the heart cannot truly be free.

So along with things being impermanent, unsatisfactory and not-self, I find it is also helpful to recollect that Dhamma 
is essentially unlocated in the world of three-dimensional space. Location is a useful tool in the physical world but in the world of mind, location, place does not apply. Threedimensional space only refers to the physical world, to the rüpa-khandha. Mind, the nāma-khandha, does not have any relationship to three-dimensional space, because mind has no material substance. Mind has no physical form; therefore three-dimensional space has no fundamental relationship to the mind.

So where is the mind? This is another helpful reflection and we can use this kind of inquiry to explore the issue as well. Ask the question: "Where is the mind?" This illuminates the presumption: "It is here". For in the clear light of awakened awareness, the wisdom faculty recognizes that even any kind of 'hereness' is not it either. So again, at the risk that this may sound abstruse or unhelpful, this is raised because it is important to look all the different habits of attachment and identification, even if they are very, very subtle.
Though we may have no sense of self, it can be that that "no sense of self" is being experienced here. And that "hereness" is also to be let go of in the practice of liberation. Dhamma is absolutely real, but it's completely unlocated. You cannot say that the Dhamma is any "where". You might say, "But it's everywhere!" But by looking at that whole dimension of experience it can be recognized that "whereness" does not apply. Allow that recognition to have its effect upon the citta.

Excerpted from The Breakthrough by Ajahn Amaro, Amaravati Publications, 2016.

Publisher's Note Springer Nature remains neutral with regard to jurisdictional claims in published maps and institutional affiliations. 